\title{
Servikal Yetmezliği Olan Gebelerde Medikal Tedavi Yeterli mi? Acil Serklaj Uygulanmalı mı?
}

\author{
Is Medical Treatment Sufficient for Pregnant Women with Cervical \\ Insufficiency? Should Emergency Cerclage be Applied?
}

\author{
Eren AKBABA
}

Muğla Sıtkı Koçman Üniversitesi Tıp Fakültesi Kadın Hastalıkları ve Doğum AD, Muğla

\begin{abstract}
$\ddot{\mathbf{O z z}}$
İkinci trimester gebelik kayıplarının \%16-20'sinden servikal yetmezlik sorumludur. $\mathrm{Bu}$ çalışmanın amacı gebeliğin ikinci trimesterinde servikal yetmezlik tanısı ile acil serklaj ve medikal tedavi uyguladığımız hastalar ile yalnızca medikal tedavi yapılan kadınların maternal, perinatal sonuçlarını karşılaştırmaktır. Bu retrospektif çalışma, önceden erken doğum hikayesi olan, gebeliği tekiz ve 16-24. hafta arasında, servikal yetmezlik tanılı, amniotik membranı vajene prolabe olmuş hastalar değerlendirilerek yapıldı. Yatak istirahati tüm hastalara önerildi, serklaj tekniği olarak McDonalds yöntemi kullanıldı. Servikal yetmezlik tanısı alan hastalara tıbbi tedavi olarak antibiyotik profilaksisi, progesteron ayrica indometasin veya nifedipin uyguland. $\mathrm{Bu}$ hastalardan 24. gebelik haftasını dolduranlara akciğer olgunlaşması için betametazon verildi. Toplam 29 hastadan 19 hastaya acil serklaj + medikal tedavi, 10 hastaya yalnızca medikal tedavi uygulandı. Acil serklaj uyguladığımız hastalardan 7'sinin, medikal tedavi uyguladığımız 2 hastanın gebeliği geç abortusla sonuçlandi. Acil serklaj + medikal tedavi uygulanan hastalarda tedavi sonrası ortalama doğuma kadar geçen süre $24.83 \pm 12.44$ gün; sadece medikal tedavi uygulananlarda ise $20.13 \pm 6.94$ gündü. Serklaj + medikal tedavi uyguladığımız hastalarda doğum için kazanılan süre istatistiksel olarak anlamlı derecede daha fazlaydı $(\mathrm{p}=0.037)$. Servikal yetmezlik tanısı alan ve 24 . gebelik haftasından sonra doğum yapan acil serklaj + medikal tedavi uygulanan hastaların 4'ünde, medikal tedavi alanların 3'ünde perinatal ölüm oldu. Acil serklaj + medikal tedavi uygulanan 19 hastanın 8 'inde, sadece medikal tedavi uygulanan 10 hastanın 5'inde canlı doğum meydana geldi. Çalıșmamızda acil serklaj uygulamalarının gebelik süresini uzattığını belirledik. Fakat acil serklaj ile kazanılan sürenin perinatal sonuçlara olumlu istatistiksel katkısı saptanmadı.
\end{abstract}

Anahtar Kelimeler: Acil Servikal Serklaj, Perinatal Sonuçlar, Servikal Yetmezlik

\section{Giriş}

Spontan erken doğumlar, perinatal morbidite ve mortalitenin en önde gelen sebeplerindendir. Erken doğum oranı Amerika Birleşik Devletleri'nde \%9,5 olarak bildirilmiştir (1). İkinci trimester gebelik kayb1 ve preterm doğumun önemli bir sebebi servikal yetmezliktir. Servikal yetmezlik insidansı

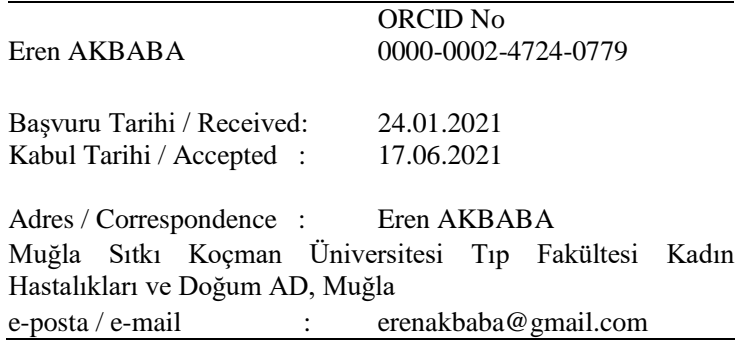

\begin{abstract}
Cervical insufficiency is responsible for $16-20 \%$ of second trimester losses. This study aims to compare the maternal and perinatal outcomes of the patients diagnosed with cervical insufficiency in the second trimester of pregnancy who underwent emergency cerclage and medical treatment with the patients, who were managed with only medical treatment. This retrospective study was conducted by evaluating the patients with a singleton pregnancy between the 1624 th weeks of gestation with a previous history of preterm labor, and diagnosis of cervical insufficiency, and prolapsed amniotic membrane in to the vagina. The cerclage was applied using the McDonald technique. Antibiotic prophylaxis, progesterone, indomethacin, or nifedipine were administered as medical treatment to the patients diagnosed with cervical insufficiency. It was found that among these patients, beta methasone was administered for lung maturation in those who completed the 24th gestational week. Out of a total of 29 patients, 19 patients received emergency cerclage and medical treatment, and 10 patients received only medical treatment. 7 of the patients who underwent emergency cerclage, and 2 patients that we applied medical treatment, resulted in late abortion. The mean delivery time after treatment was $24.83 \pm 12.44$ days in patients who applied emergency cerclage + medical treatment; and was $20.13 \pm 6.94$ days in patients who only applied medical treatment. The extra time for delivery was statistically significantly higher in the patients we applied cerclage + medical treatment $(\mathrm{p}=0.037)$. Perinatal death occurred in 4 of the patients diagnosed with cervical insufficiency who received emergency cerclage + medical treatment and 3 of the patients who received medical treatment after their 24th gestational week. Live births occurred in 8 of 19 patients in whom emergency cerclage + medical treatment was applied, and in 5 of 10 patients who have applied only medical treatment. In our study, we determined that emergency cerclage applications prolong the gestational period. However, no positive statistically significant contribution was found in the time gained by emergency cerclage on perinatal outcomes.

Keywords: Emergency Cervical Cerclage, Perinatal Outcomes, Cervical Insufficiency
\end{abstract}

tüm gebelikler içinde \%0.5-1'dir (2). İkinci trimester gebelik kayıplarının \%16-20'sinden servikal yetmezlik sorumludur (3). İkinci trimester gebelik kayıpları veya ikinci trimester erken doğumların (16-28 gebelik haftası) rekürrens oranı \%7 olarak saptanmıştır (4). Servikal yetmezliğin net bir tanımı yoktur, genellikle serviksde ikinci veya erken üçüncü trimesterde rahim ağzının ağrısız, progresif dilatasyonu ile ilişkilidir. Servikal yetmezlik amniotik membranın prolapsusu ve rüptürü nedeniyle 2. trimesterin sonunda gebelik kaybı veya erken doğumla sonuçlanan bir süreçtir (5). Servikal yetmezlik için birçok test (servikal kanal genişliğinin histerosalpingogram ile değerlendirilmesi, servikal dilatatörlerin 9 nolu hegar bujinin internal kanalı dirençsiz geçebilmesi) bildirilmiş olsa da tanısal bir test yoktur (6). Serklaj 
endikasyonları içinde en önemlisi hastanın ağrı semptomu olmadan 2. trimester gebelik kaybı ve erken doğum hikayesi olmasıdır (7) .Servikal serklaj, servikal yetmezlik hikayesi olan kadınların primer tedavi şeklidir. Üç tip servikal serklajdan bahsedilebilir; 1. Profilaktik serklaj, en az $3 \mathrm{kez}$ ağrısız servikal dilatasyon ve açılma nedeni ile erken doğum hikayesi olanlarda, 2. Terapötik serklaj, en az $1 \mathrm{kez}$ erken doğum hikayesi olan, gebeliği $<24$ hafta ve serviksinde değişiklik olanlarda (transvajinal ultrasonda servikal uzunluk $<25 \mathrm{~mm}$ saptanan gebeler), 3. Acil serklaj, 24. gebelik haftasından önce enaz $3 \mathrm{~cm}$ servikal dilatasyonu ya da amniotik membranın vajene prolabe olan hastalarda uygulanır. Acil serklajın yatak istirihati ya da indometazine göre maternal morbidite ve mortaliteyi artırmadan gebelik süresini artırdığı bildirilmiştir (8). Bununla birlikte serklaj yapılan hastalarda en sık karşılaşılan komplikasyonlar, koriyoamnionit, erken membran rüptürüdür (9). Acil serklaj uygulanan hastalardaki temel kaygı doğuma kadar kazanılan sürenin anne ve bebek için oluşabilecek komplikasyonlar açısından güvenli olup olmadığıdır (10).

$\mathrm{Bu}$ çalışmanın amacı gebeliğin ikinci trimesterinde servikal yetmezlik tanısı ile acil serklaj ve medikal tedavi uyguladığımız hastalar ile serklaj uygulamayıp yalnızca medikal tedavi ve yatak istirahati yapılan kadınların maternal, perinatal sonuçlarını karşılaştırmaktır.

\section{Gereç ve Yöntem}

Bu çalışma Muğla Sıtkı Koçman Üniversitesi Tıp Fakültesi yerel Etik Kurulu tarafından onaylanmıştır (Onay tarihi: 14 Nisan 2021 ve No: 8/IV). Tüm katılımcilardan Helsinki Bildirgesi'ne uygun olarak yazılı ve ameliyat olacak tüm kadınlardan sözlü ve yazılı bilgilendirilmiş cerrahi onam alındı.

Bu retrospektif çalışma Mart 2012 -Aralık 2020 tarihleri arasında, Sağlık Bakanlığı Muğla Eğitim Araştırma Hastanesi Kadın Hastalıkları ve Doğum kliniğinde, daha önceden erken doğum hikayesi olan, 16-24. gebelik haftaları arasında, tekiz gebeliği olan, servikal yetmezlik tanıl, amniotik membranı vajene prolabe olmuş 29 hasta değerlendirilerek yapıldı. Erken membran rüptürü, koriyoamnionit, dekolman plasenta, aktif vajinal kanama, plasenta previatanılı hastalar çalışmaya alınmadı. Hastaların diğer demografik ve klinik özelliklerini içeren veriler elektronik tıbbi kayıtlardan, hasta ve bebek dosyalarından derlendi ve kayıt edildi.

Servikal dilatasyon ve kısalma pelvik ve/veya spekulum muayenesi ile ayrica transvajinal ultrason ile değerlendirilmişti. Serviksinde en az $3 \mathrm{~cm}$ dilatasyonu olan, inspeksiyonda amniotik membranı görülebilen, ikinci trimester en az 1 gebelik kayıbı hikayesi olan hastalara acil serklaj önerilmişti. Serklaj tekniği olarak McDonalds yöntemi kullanılmıştır. Medikal tedavi olarak, tüm hastalara yatak istirahati önerilmiştir ayrıca antibiyotik profilaksisi (Sefazolin sodyum 4 gram/gün parenteral), progesteron (haftada bir kez $500 \mathrm{mg}$ hidroksi progesteron kaproate, günde $3 \times 200 \mathrm{mg}$ vajinal mikronize progesteron),tokolitik ajan olarak 32. gebelik haftasından küçük gebeliği olanlara indometazin (100 mg suppozituar, $6 \times 25 \mathrm{mg}$ oral), 32. Gebelik haftasından büyük gebeliği olanlara nifedipin $(6 \times 20 \mathrm{mg}$ sublingual), gebeliği 24. haftayı aşan kadınlara fetal akciğer matürasyonu için betametazon ( $24 \mathrm{mg}$, intramuskuler) uygulanmıştır.

Klinik koryoamniyonit tanısı, maternal ateş $\left(\geq 38.0^{\circ} \mathrm{C}\right)$ ve aşağıdaki 5 klinik belirtiden 2 veya daha fazlasının saptanması ile konuldu. Maternal taşikardi (dakikada> 100 atımlık kalp hızı), fetal taşikardi (dakikada 160 atımdan yüksek kalp hızı), uterus hassasiyeti, pürülan veya kötü kokulu amniyotik sıv1 veya vajinal akıntı ve maternal lökositoz (beyaz kan hücresi sayısı $>15.000 / \mathrm{mm}^{3}$ ) (11). Rest plasenta tanısı ise doğum sonrası uzun süreli ve tekrarlayan kanama ve doppler ultrasonda intracaviter yoğun kanlanması olan kitle imajı olanlara kondu (12).

Servikal yetmezlik tanısı konan hastalar acil serklaj ve medikal tedavi uygulanan hastalar ile yalnızca medikal tedavi alanlar hastaların gebelik süreleri, doğum şekilleri, hastaların doğum haftaları, tanı konması ile doğuma kadar geçen süre, maternal komplikasyonlar (koriyoamnionit, uterinatoni, rest plasenta), bebek doğum kiloları, fetal yoğun bakım ihtiyaçları, fetal komplikasyonlar ve fetal ölümler açısından karşılaştırıldı.

Cerrahi Teknik: McDonalds serklaj, regional anestezi altında, litotomi pozisyonunda ve $30^{\circ}$ trendelenburg sağlanarak yapıldı. Serviks üst ve alt dudağından ring forceps ile tutuldu, prolabe olan amniotik membran over pensine tutturulmuş islak gazlı bezle uterin kaviteye doğru ittirildi. $5 \mathrm{~mm}$ genişliğinde (Ethicon, Mersilene, Somerville, NJ, USA) sütür materyali kullanılarak serviks uteri ile ön vajinal mukoza birleşim hizasında, internal servikal osun üst sınırında, servikal kanal ve amniotik mebranlardan kaçınılarak, serviks dairesel, çevrelice sütüre edilip Mersilen sütür sol lateral forniksde düğümlenerek servikal açıklık kapatıldı.

İstatistiksel analiz: Sürekli değişkenlerin normal dağılım uygunluğu Kolmogorov Smirnov testi kullanılarak değerlendirildi. Normal dağılım gösteren veriler; ortalama \pm standart sapma, normal dağılım göstermeyen veriler ise medyan(minimummaksimum) olarak ifade edildi. Kategorik değişkenler frekans(n) ile gösterildi ve gruplar arasında farklılık olup olmadığı ki-kare testi ile incelendi. İki bağımsız grubun karşılaştırılmasında bağımsız örneklemler $\mathrm{t}$ testi, dağılımı normal olmayan verilerin karşılaştırmasında Mann-Whitney U testi kullanıldı.Elde edilen veriler SPSS, Windows 22.0(SPSS Inc., Chicago, IL, USA) sürümü kullanılarak analiz edildi. 0.05'ten daha düşük bir $\mathrm{p}$ değerinde farklılıklar anlamlı olarak kabul edildi. 


\section{Bulgular}

Erken doğum hikayesi olan, servikal yetmezlik tanısı konan 29 hasta çalışmaya alındı. Tüm hastalarımızın servikaldilatasyonu3cmden fazlayd, spekulum ile vajinal inspeksiyonda amniotik membran görülebiliyordu. Acil serklaj önerilen 29 hastadan serklaj prosedürünü kabul eden 19 hastaya McDonalds tekniği ile acil serklaj ve medikal tedavi uygulandı, diğer 10 hastaya yalnızca medikal tedavi uyguland. İki grubun demografik özellikleri benzerdi (Tablo 1).

Tablo 1. Acil serklaj+medikal tedavi uygulanan hastalar ile yalnızca medikal tedavi uygulanan hastaların demografik özellikleri

\begin{tabular}{|c|c|c|c|}
\hline & $\begin{array}{l}\text { Acil serklaj } \\
\quad(n=19)\end{array}$ & $\begin{array}{c}\text { Medikal } \\
\text { tedavi } \\
(\mathrm{n}=10) \\
\end{array}$ & $\mathrm{p}$ \\
\hline Yaş (yıl) & $30(21-42)$ & $29(22-38)$ & 0.186 \\
\hline VKİ $\left(\mathrm{kg} / \mathrm{m}^{2}\right)$ & $26.9 \pm 3.1$ & $27.6 \pm 2.9$ & 0.095 \\
\hline Gravida & $3(2-11)$ & $3(2-9)$ & 0.049 \\
\hline Parite & $2(1-6)$ & $2(1-5)$ & 0.814 \\
\hline $\begin{array}{l}\text { Servikal yetmezlik } \\
\text { tanısı konan hafta } \\
\text { (hafta) }\end{array}$ & $20(15-25)$ & $21(16-25)$ & 0.149 \\
\hline $\begin{array}{l}\text { Servikal uzunluk } \\
(\mathrm{mm})\end{array}$ & $18.23 \pm 2.55$ & $20.16 \pm 1.91$ & 0.071 \\
\hline
\end{tabular}

Acil serklaj + medikal tedavi uyguladığımız hastalar ile yalnızca medikal tedavi uyguladığımız hastaların obstetrik sonuçları karşılaştırıldı (Tablo 2). Acil serklaj + medikal tedavi uyguladığımız 19 hastadan 7'sinin, medikal tedavi uyguladığımız 10 hastadan 2'sinin gebeliğgi $<24$. gebelik haftasında geç abortusla sonuçlandı. Her iki gruptada servikal yetmezlik tanısı konulan hastalardan $>34$. gebelik haftasında doğum yapan hasta olmadi. Servikal yetersizlik tanısı konularak acil serklaj uygulanan hastaların doğuma kadar geçen süresi medikal tedavi uygulananlardan istatistiksel anlamlı düzeyde fazlayd $1(p=0.037)$.

Tablo 2. Acil serklaj + medikal tedavi uygulanan hastalar ve yalnızca medikal tedavi uygulanan hastaların obstetrik ve perinatal sonuçlarının karşılaştırması

\begin{tabular}{lccc}
\hline $\begin{array}{l}\text { Obstetrik/Perinatal } \\
\text { değişkenler }\end{array}$ & $\begin{array}{c}\text { Acil serklaj } \\
(\mathrm{n}=19)\end{array}$ & $\begin{array}{c}\text { Medikal tedavi } \\
(\mathrm{n}=10)\end{array}$ & $\mathrm{p}$ \\
\hline $\begin{array}{l}\text { Geç spontanabortus } \\
(<2 \text { hafta) }\end{array}$ & 7 & 2 & \\
$\begin{array}{l}\text { Doğumdaki gebelik } \\
\text { haftas1 }\end{array}$ & $29.75 \pm 3.02$ & $28.75 \pm 1.91$ & 0.239 \\
$\begin{array}{l}\text { Tanı konmasi ile doğuma } \\
\text { kadar geçen süre, (gün) }\end{array}$ & $24.83 \pm 12.44$ & $20.13 \pm 6.94$ & $0.037^{*}$ \\
$\begin{array}{l}\text { Doğum şekli } \\
\text { NSVD }\end{array}$ & 6 & & \\
Sezaryen & 6 & 5 & 0.670 \\
Koryoamnionit & 1 & 3 & \\
$\begin{array}{l}\text { UterinAtoni } \\
\text { Rest plasenta }\end{array}$ & 1 & 0 & \\
\hline
\end{tabular}

NSVD: Normal spontan vajinal doğum

Acil serklaj + medikal tedavi uyguladığımız hastalar ile yalnızca medikal tedavi yaptı̆̆ımız hastaların perinatal sonuçları karşılaştırıldı (Tablo 3). Servikal yetmezlik tanısı konan $>24$. gebelik haftasında doğum yapan gebelerden acil serklaj medikal tedavi uygulananlardan 4'ünde, medikal tedavi uygulanan 3 hastada, perinatal bebek ölümü saptandı. Her iki grubun diğer perinatal sonuçları benzerdi.

Tablo 3. Acil serklaj + medikal tedavi uygulanan hastalar ile yalnızca medikal tedavi uygulanan hastaların perinatal sonuçlarının karşılaştırması

\begin{tabular}{lccc}
\hline Perinatal değişkenler & $\begin{array}{c}\text { Acil serklaj } \\
(\mathrm{n}=19)\end{array}$ & $\begin{array}{c}\text { Medikal tedavi } \\
(\mathrm{n}=10)\end{array}$ & $\mathrm{p}$ \\
$\begin{array}{l}\text { Bebek doğum ağırlığı } \\
\text { (gr) }\end{array}$ & $1620 \pm 562.14$ & $1377.50 \pm 367.06$ & 0.098 \\
Yeni doğan YBÜ & 10 & 7 & \\
ihtiyacı & 8 & 5 & \\
Yenidoğan sağkalım & 4 & 3 & \\
Yenidoğan mortalite & & &
\end{tabular}

\section{Tartışma}

Bu çalışmada amniotik membranı vajene prolabe olmuş, servikal yetmezlik tanısı ile acil serklaj ve medikal tedavi uyguladığımız hastalar ile serklaj işlemini kabul etmeyen yalnızca medikal tedavi yaptığımız hastaların obstetrik ve perinatal sonuçlarını karşılaştırdık. Serklaj ve medikal tedavi uyguladığımız hastalar ile yalnızca medikal tedavi verdiğimiz hastaların doğumdaki ortalama gebelik haftaları benzerdi sırasılla $29.75 \pm 3.02 ; 28.75 \pm 1.91$; $\mathrm{p}=0.239$. Acil serklajın tanımı ve uygulama kriterleri hala tam olarak açığa kavuşmuş değildir. Bu konu ile ilgili güncel yalnız 1 randomize çalışma vardır (13). $\mathrm{Bu}$ randomize çalışmada 16 tekiz gebeliği olan 10 hastaya acil serklaj, 6 hastaya yatak istirahati ve medikal tedavi uygulanmıştır. Hasta sayısı az olan bu çalışmada serklaj grubunda ortalama doğum haftası $29.9 \pm 8.4$ iken, yatak istirahati ve medikal tedavi grubunda ise $25.9 \pm 4.3$ hafta olarak saptanmış ve acil serklaj uygulamalarında preterm doğum oranlarının yatak istirahati ve medikal tedavi önerilenlere göre daha az olduğu bildirilmiş olsa da istatistiksel fark saptanmamıştır.

Terkildsen ve ark.'nın (14) servikal yetmezliği olan amniotik membranı prolabe olan hastalar ile membranı prolabe olmayan hastalarda acil serklaj uygulamasının etkinliğini değerlendirdiği çalışmada amniotik membranı prolabe olmayan kadınlarda acil serklajın gebelik süresini uzattığını saptamışlardır.

Servikal yetmezlik tanısı konan hastaların preterm doğumunu öngörmede 4 kriter önemlidir: obstetrik hikaye; servikal dilatasyon; amniotik membranların vajene prolabe olmasi; ve enfeksiyondur (15). Benzer şekilde prolabe membranı olanlar, $3 \mathrm{~cm}$ den daha fazla servikal dilatasyonu olanlar, sistemik enfeksiyonu olanlar, ileri yaş gebeler ve 22. gebelik haftasından sonra serklaj uygulanan hastaların klinik sonuçlarının daha kötü olduğu bildirilmiştir (16).

Bizim çalışmamızda acil serklaj + medikal tedavi uyguladığımız hastalarda doğuma kadar kazanılan gün sayıs 24.83 \pm 12.44 ; yalnızca medikal tedavi uyguladığımı hastalarda $20.13 \pm 6.94$; olarak 
saptadik. Acil serklaj + medikal tedavi uyguladığımız hastalarda kazanılan gün sayısı yalnızca medikal tedavi uygulanan hastalar göre anlamlı düzeyde fazlayd $1 \quad(\mathrm{p}=0.037)$. Aoiki ve ark.'nın (17) çalışmasında acil serklaj uyguladıkları hastalarda doğuma kadar kazanılan süre ortalama 44 gün, yatak istirahati önerdikleri hastalarda 12.5 gün olarak saptamışlardır. M. Althuisius ve ark. (13)'nın prospektif çalışmasında acil serklaj uygulanan hasta grubunda doğuma kadar kazanılan süre $54 \pm 47$ gün (95\% CI, 26-82), medikal tedavi ve yatak istirahati önerilen grupta $20 \pm 28$ gün $(95 \% \mathrm{CI}, 0-41), \mathrm{p}=0.46$ olarak saptanmıştır

Serklaj uygulamaları erken membran rüptürü riskini artırmaktadır (18). Acil serklaj uygulamalarında olumlu fetal sonuçlar hedeflenirken korioamnionit, sepsis gibi maternalfetal ciddi komplikasyonlardaki risk artıșı da hasta ile paylaşılmalıdır (19). Çalışmamızda acil serklaj uyguladığımız 1 hasta korioamnionit, 3 hasta rest plasenta, 1 hasta uterinatoni ile komplike oldu. Medikal tedavi uyguladığımız 1 hastada rest plasenta gelişti bu grupta korioamnionit tanıs1 koyduğumuz hasta yoktu.

Acil serklaj uyguladığımız hastalar ile servikal yetmezlik kliniğini medikal tedavi ile yönetmeye çalıştığımız hastaların yenidoğan bebek kiloları arasında istatistiksel fark saptanmadı sirasiyla $1620 \pm 562.14$ g; $1377.50 \pm 367.06$ g; p=0.098. Costave ark. serklaj uyguladığı grupta yenidoğan ortalama kilosunu $1468.3 \mathrm{~g}$, yatak istirihati önerdikleri grupta 861.2 g olarak saptamış 2 grup arasında istatistiksel fark saptamamıştır (20). Buna karşın JH Stupin ve ark. (21) acil serklaj uyguladığ hastalarda yenidoğan ortalama kilosunu $1340 \mathrm{~g}$, olarak saptamış ve ileri dercede anlamlı olarak serklajın perinatal sonuçlara olumlu katkısı olduğunu bildirmiştir.

Bizim çalışmamızda servikal yetmezlik tanısı ile acil serklaj + medikal tedavi uyguladığımız 19 hastadan 8'inin bebeği sağ kalırken, yalnızca medikal tedavi uyguladığımız 10 hastadan 5'inin bebeği sağ kaldı. Olatunbosun ve ark. (22), servikal yetmezlik tanılı, servikal dialtasyonu $4 \mathrm{~cm}$ den daha fazla olan, 20-27. gebelik haftaları arasındaki acil serklaj uyguladıkları 23 hasta ile yatak isitirahati uyguladıkları 20hastanın obstetrik ve perinatal sonuçlarını karşılaştırmışlardır. Bu çalışmada acil serklaj uygulanan hastaların doğum haftaları yatak istirhati uygulanan hastalardan daha fazla olarak saptamış (sırasıyla $33 \pm 4.4 ; \quad 28.8 \pm 4.4 ; \quad \mathrm{p}=0.001$ ) olmasına rağmen bizim çalışmamızla benzer olarak serklaj uygulanan grup ile istirahat önerilen hastalar arasında yenidoğan sağkalım oranının benzer olduğunu bildirmişlerdir. M. Althuisius ve ark. (13) acil serklaj uygulanan hastalardan 16 yenidoğandan 9'unun hayatta kaldığını, yatak istirahat grubundaki 14 yenidoğanın 4 'ünün hayatta kaldığını bildirmiştir. Ciancimino L ve ark. (23) servikal yetmezlik tanılı acil serklaj uyguladıkları 12 gebeyi içeren çalışma grubunda yenidoğan sağ kalım oranını \%83.3, Costa ve ark. (24) acil serklaj uyguladıkları hastalarda yenidoğan sağkalım oranını \%47.4, yalnızca medikal tedavi verdikleri hastalarda \%36.3 olarak saptamıştır ( $p>0.05$ ). Çavus ve ark.(20) 20 hastalık çalışma grubunda \%90 yenidoğan sağ kalımı oranı bildirmişlerdir. Çalışmalar arasındaki farklılıkların başlıca sebepleri çalışılan hasta sayılarının az olması, doğumun gerçekleştiği gebelik haftası, yeni doğan bebek kilo dağılımının benzer olmaması, yenidoğan yoğun bakım üniteleri ve ekipleri arasındaki farklılıklar olabilir.

Çalışmamızın zayıf yönleri retrospektif olması ve vaka sayısının az olmasıdır. Hastalarımızın acil serklaj ve medikal tedavi uygulamaları tek merkezde yapılmış olsa da yenidoğan yoğun bakım tedavileri farklı merkezlerde yapılmıştır, bu durum perinatal sonuçlar açısından çalışmamızın zayıf yönlerinden kabul edilebilir.

Biz çalışmamızda acil serklaj uygulamalarının erken doğumları azalttığını, gebelik süresini uzattığını belirledik. Fakat acil serklaj ile kazanılan sürenin perinatal sonuçlara olumlu istatistiksel katkısı saptanmadı. Hakkında sınırlı verisi olan, acil serklaj uygulamaları ve perinatal sonuçları ile ilgili çalışmamızın literatüre katkısı olacağ düşüncesindeyiz. Daha fazla hastayı içeren prospektif randomize çalışmalar acil serklajın etkinliği konusunda daha fazla kanaat oluşturabilir.

Etik Kurul Onayı: Muğla Sitkı Koçman Üniversitesi Tıp Fakültesi Yerel Etik Kurulu'ndan 14 Nisan 2021 tarih ve 8/IV kayıt numarası ile etik kurul onayı alınmıştır.

\section{Kaynaklar}

1. Osterman MJK, Martin JA. Timing and Adequacy of Prenatal Care in the United States, 2016. National vital statistics reports : from the Centers for Disease Control and Prevention, National Center for Health Statistics. Natl Vital Stat Rep. 2018;67(3):1-14

2. Marcellin L. Prevention of preterm birth by uterine cervical cerclage. J Gynecol Obstet Biol Reprod (Paris). 2016;45(10):1299-323.

3. Kurup M, Goldkrand JWJAjoo, gynecology. Cervical incompetence: elective, emergent, or urgent cerclage. Am J Obstet Gynecol. 1999;181(2):240-6.

4. Sneider K, Christiansen OB, Sundtoft IB, Langhoff-Roos J. Recurrence of second trimester miscarriage and extreme preterm delivery at 16-27 weeks of gestation with a focus on cervical insufficiency and prophylactic cerclage. Acta Obstet Gynecol Scand. 2016;95(12):1383-90.

5. ACOG Practice Bulletin No.142: Cerclage for the management of cervical insufficiency. Obstet Gynecol. 2014;123(2 Pt 1):372-9.

6. Shennan A, Jones B. The cervix and prematurity: aetiology, prediction and prevention. Semin Fetal Neonatal Med. 2004;9(6):471-9.

7. Rust OA, Atlas RO, Jones KJ, Benham BN, Balducci J. A randomized trial of cerclage versus no cerclage among patients with ultrasonographically detected second-trimester preterm dilatation of the internal os. Am J Obstet Gynecol. 2000;183(4):830-5.

8. Steenhaut $\mathrm{P}$, Hubinont $\mathrm{C}$, Bernard $\mathrm{P}$, Debiève $\mathrm{F}$. Retrospective comparison of perinatal outcomes following 
emergency cervical cerclage with or without prolapsed membranes. Int J Gynaecol Obstet. 2017;137(3):260-4

9. Wierzchowska-Opoka M, Kimber-Trojnar Ż, LeszczyńskaGorzelak B. Emergency Cervical Cerclage. J Clin Med. 2021;10(6):1270

10. Pang Q, Jia X, Chen L. Perinatal Outcomes After Emergency Cervical Cerclage for Cervical Insufficiency with Prolapsed Membranes. Med Sci Monit. 2019;25:4202-6.

11. Conde-Agudelo A, Romero R, Jung EJ, Garcia Sánchez Á J. Management of clinical chorioamnionitis: an evidence-based approach. Am J Obstet Gynecol. 2020;223(6):848-69.

12. Shitanaka S, Chigusa Y, Kawahara S, et al. Conservative management for retained products of conception after less than 22 weeks of gestation. J Obstet Gynaecol Res. 2020;46(10):1982-7.

13. Althuisius SM, Dekker GA, Hummel P, van Geijn HP. Cervical incompetence prevention randomized cerclage trial: emergency cerclage with bed rest versus bed rest alone. Am J Obst Gynecol. 2003;189(4):907-10.

14. Terkildsen MF, Parilla BV, Kumar P, Grobman WA. Factors associated with success of emergent second-trimester cerclage. Obstetrics and gynecology. 2003;101(3):565-9.

15. Fuchs F, Senat MV, Fernandez H, Gervaise A, Frydman R, Bouyer J. Predictive score for early preterm birth in decisions about emergency cervical cerclage in singleton pregnancies. Acta Obstet Gynecol Scand. 2012;91(6):744-9.

16. Namouz S, Porat S, Okun N, Windrim R, Farine D. Emergency cerclage: literature review. Obstet Gynecol Survey. 2013;68(5):379-88.

17. Aoki S, Ohnuma E, Kurasawa K, Okuda M, Takahashi T, Hirahara F. Emergency cerclage versus expectant management for prolapsed fetal membranes: a retrospective, comparative study. J Obstet Gynaecol Res. 2014;40(2):381-

18. Chen Q, Chen G, Li N. Clinical effect of emergency cervical cerclage and elective cervical cerclage on pregnancy outcome in the cervical-incompetent pregnant women. Arch Gynecol Obstet. 2018;297(2):401-7.

19. Debby A, Sadan O, Glezerman M, Golan A. Favorable outcome following emergency second trimester cerclage. Int J Gynaecol Obstet. 2007;96(1):16-9.

20. Cavuş Y, Uysal A, Balsak D, Acar Z, Ínce Z, Uysal F. Emergency cervical cerclage: effect on pregnancy outcome and mode of delivery. J Matern Fetal Neonatal Med. 2014;27(1):80-3

21. Stupin JH, David M, Siedentopf JP, Dudenhausen JW. Emergency cerclage versus bed rest for amniotic sac prolapse before 27 gestational weeks. A retrospective, comparative study of 161 women. Eur J Obstet Gynecol Reprod Biol. 2008;139(1):32-7.

22. Olatunbosun OA, al-Nuaim L, Turnell RW. Emergency cerclage compared with bed rest for advanced cervical dilatation in pregnancy. Int Surg. 1995;80(2):170-4.

23. Ciancimino L, Laganà AS, Imbesi G, Chiofalo B, Mancuso A, Triolo O. Evaluation of Maternal-Fetal Outcomes After Emergency Vaginal Cerclage Performed With ShirodkarMcDonald Combined Modified Technique. J Clin Med Res. 2015;7(5):319-23

24. Costa MMF, Amorim Filho AG, et al. Emergency cerclage: gestational and neonatal outcomes. Rev Assoc Med Bras (1992). 2019;65(5):598-602. 